\title{
CuZn Elektrotundan Zn’nin Uzaklaştırılmasının Hidrojen Çıkış Davranışı Üzerine Etkisi
}

\author{
Serap TOPRAK DÖŞLÜ* \\ Beslenme ve Diyetetik Bölümü, Sağlık Bilimleri Fakültesi, Mardin Artuklu Üniversitesi, Mardin, Türkiye \\ Merkezi Araştırma Laboratuvarı, Mardin Artuklu Üniversitesi, Mardin, Türkiye \\ seraptoprak@artuklu.edu.tr
}

Öz: Hidrojen üretiminde, elektrokimyasal yolla suyun ayrıştırılmasında yüksek katalitik aktiviteye sahip ve kararlı elektrotların geliştirilmesi çok önemlidir. Burada, CuZn elektrotunun fabrikasyonunu yapmak için ucuz alkali uzaklaştırma yöntemi kullanılmış ve bu yöntem elektrota, hidrojen oluşum reaksiyonu (HER) için yüksek yüzey alanı ve verimli aktif merkezler sağlamıştır. CuZn elektrotu karakterize etmek için, taramalı elektron mikroskop (SEM), enerji dağılımlı X-Işını (EDX), atomik kuvvet mikroskop (AFM) ve Dönüşümlü voltametri (CV) tekniklerinden yararlanılmıştır. CuZn elektrotunun hidrojen oluşum karakteristiği 1,0 M KOH çözeltisinde, bakır kaplı bakır elektrot $(\mathrm{Cu} / \mathrm{Cu})$ ile kıyaslanmıştır. SEM analizlerine göre, $\mathrm{Cu} / \mathrm{Cu}$ elektrotta bakır nano-tanecikler yüzeye dağılırken, CuZn elektrotta karnabahara benzeyen şekiller elde edilmiştir. Metallerin karakteristik pikleri CV ve EDX spektrumlarında ortaya çıkmıştır. HER etkinlikleri değerlendirildiğinde, $\mathrm{CuZn}$ elektrot $(0.309$ $\left.\mathrm{mA} \mathrm{cm} \mathrm{cm}^{-2}\right), \mathrm{Cu} / \mathrm{Cu}$ elektrot $\left(0.043 \mathrm{~mA} \mathrm{~cm}{ }^{-2}\right)$ ile kıyaslandığında yüksek yük değişimi akım yoğunluğu elde edilmiştir. Ayrıca, $\mathrm{CuZn}$ elektrot, $50 \mathrm{~mA} \mathrm{~cm}{ }^{-2}$ akım yoğunluğunda daha düşük aşırı gerilime ve daha düşük Tafel eğimine sahiptir. Bu CuZn elektrotun $\mathrm{Cu} / \mathrm{Cu}$ elektrotundan daha yüksek HER performansına sahip olduğu anlamına gelir. Bu yüksek katalitik aktivite, alkali uzaklaştırma nedeniyle yüksek yüzey alanı ve $\mathrm{Zn}$ ve $\mathrm{Cu}$ metallerinin sinerjistik etkisi ile açıklanabilir. Bu deneylere ek olarak, CuZn elektrot bazik ortamda 18000 saniye boyunca oldukça yüksek kararlılık ve dayanıklılık göstermiştir.

Anahtar kelimeler: Hidrojen oluşum reaksiyonu, CuZn elektrot, Elektrokatalizör, Alkali uzaklaştırma.

\section{The Effect of Leaching of Zn from CuZn on Hydrogen Evolution Behavior}

\begin{abstract}
It is very important the development of electrodes with high catalytic activity and stable in the hydrogen production via electrochemical water splitting. Herein, facile alkaline leaching procedure is used to fabricate $\mathrm{CuZn}$ electrode and this procedure provides to electrode high surface area and sufficient active centers for hydrogen evolution reaction (HER). Scanning electron microscopy (SEM), Energy Dispersive X-Ray (EDX), atomic force microscopy (AFM) and Cyclic voltammetry (CV) are utilized to characterize leached electrode $(\mathrm{CuZn})$. Hydrogen evolution characteristic of $\mathrm{CuZn}$ is compared to copper coated copper $(\mathrm{Cu} / \mathrm{Cu})$ electrode in $1.0 \mathrm{M} \mathrm{KOH}$ solution. While copper nano-particles are distributed over the copper surface for $\mathrm{Cu} / \mathrm{Cu}$, cauliflowers like shapes are obtained for $\mathrm{CuZn}$, according to SEM analysis. Characteristic peaks of metals are appeared in the CV and EDX spectrums. In the evaluation of the HER activity, high exchange current density is obtained at $\mathrm{CuZn}$ electrode $\left(0.309 \mathrm{~mA} \mathrm{~cm}{ }^{-2}\right)$ in comparison of $\mathrm{Cu} / \mathrm{Cu}\left(0.043 \mathrm{~mA} \mathrm{~cm}{ }^{-2}\right)$. Moreover, $\mathrm{CuZn}$ electrode has smaller Tafel slope and overpotential at $50 \mathrm{~mA} \mathrm{~cm}^{-2}$, indicating that $\mathrm{CuZn}$ electrode is higher HER performance than $\mathrm{Cu} / \mathrm{Cu}$. This high catalytic activity can be expressed with increasing high surface area due to leaching procedure and synergistic effect of $\mathrm{Zn}$ and $\mathrm{Cu}$ metals. In addition to these experiments, CuZn electrode shows very high stable and durable structure over $18000 \mathrm{~s}$ in basic media.
\end{abstract}

Key words: Hydrogen evolution reaction, CuZn electrode, Electrocatalyst, Alkaline leaching.

\section{Giriş}

Sanayi devriminden sonra, petrol, kömür ve doğal gaz gibi karbon kaynaklı fosil yakıtlar insan hayatının vazgeçilmez enerji kaynakları olmuşlardır. Dünya nüfusundaki artış ve endüstriyel gelişmeler ile birlikte Dünya iklim değişikliği, çevresel sorunlar ve enerji sıkıntısı gibi çok önemli krizlerle karşı karşıya kalmıştır. Amerika'daki Enerji Bilgi İdaresine göre toplam Dünya enerji tüketimi 2015 de 575 Btu(British Thermal Unit, İngiliz Isı Birimi)'dan, 2040 yılında \%28,5 artışla 739 Btu'ya artacağını bildirmiştir. Azalan enerji kaynakları ve artan çevresel sorunlar insanlığı sürdürülebilir enerji kaynakların bulunmasına yöneltmiştir. Bunlar arasında hidrojen içerdiği yüksek enerji yoğunluğu (143 MJ/kg) ve temiz olması nedeniyle ön plana çıkmaktadır[1].

Hidrojen günümüzde en çok fosil kaynaklı yakıtlardan üretilmekte ve bu durum enerji krizini çözmede pek ideal bir yol değildir. Bu nedenle daha sürdürülebilir ve çevreci yöntemlerin kullanılması gerekmektedir. Bu özelliklere sahip yöntem ise suyun ayrıştırılması yöntemi olup bunlar içerisinde en ideali elektrolizdir. Su elektroliz edildiğinde katotta hidrojen oluşum reaksiyonu (HER), anotta ise oksijen oluşum reaksiyonu (OER) içeren yarı reaksiyonlar meydana gelir. Alkali ortamda suyun elektroliz edilebilmesi için teorik olarak 1,23 V'luk

\footnotetext{
* Sorumlu yazar: seraptoprak@artuklu.edu.tr. Yazarların ORCID Numarası: 0000-0002-5455-8179
} 
bir elektrik enerjisi uygulanmalıdır. Fakat sistemdeki diğer aşırı gerilimler (anodik aşırı gerilim, katodik aşırı gerilimi vs.) bu uygulanan enerji miktarını arttırır[2]. Burada amaç sistemdeki aşırı gerilimleri düşürmektedir. Bunun için ise katotta kullanılan elektrokatalizörlerin yüksek etkinliğe ve kararlı yapıya sahip olması istenir. Bu sayede maliyetin düşmesi sağlanarak ekonomik yolla hidrojen üretimi gerçekleşir. Platin (Pt) genellikle suyun elektrolizinde kullanılan en etkin ve kararlı elektrokatalizördür. Fakat yüksek fiyatı ve doğada az bulunması onun ticari uygulamalarda kullanılmasını sınırlamaktadır $[3,4]$. Çözüm, düşük miktar içeren Pt elektrokatalizörlerin veya yüksek etkinliğe sahip Pt içermeyen elektrokatalizörlerin kullanılmasıdır. Demir (Fe), Kobalt (Co) ve Nikel (Ni) metalleri ucuz olmasına rağmen, düşük etkinliğe ve çözelti ortamında korozyona uğraması nedeniyle pek tercih edilmemektedir. Etkinliği ve korozyon direncini arttırmak için ikili alaşımlar yapılarak, bu sayede yüzey morfolojiler değiştirilmekte ve geniş yüzey alanlı elektrokatalizörler elde edilmektedir [5]. Bunlara örnek olarak $\mathrm{NiCu}[6], \mathrm{FeCo}[7], \mathrm{NiCo}[8], \mathrm{NiMo}[9]$ elektrokatalizörleri verilebilir. Bu elektrokatalizörlerde aşırı gerilimler düşürülerek yüksek etkinlikler elde edilmiștir.

Elektrokimyasal HER için iyi bir katalizör, aşırı potansiyeli düşürmeli ve dolayısıyla elektrokimyasal prosesin verimliliğini artırmalıdır. Aşııı potansiyeli ve onset potansiyeli düşük ve akım değeri yüksek katalizörler, yüksek HER aktivitesine sahiptir[10]. Bu durumda, HER aktivitesi için hazırlanan katalizörlerin aşırı potansiyeli ve akım yoğunlukları önem kazanmaktadır.

Aşırı gerilimin düşürülmesinde ve etkinliğin arttırılmasında, elektrokatalizörün yüzey alanının genişletilmesi önemli rol oynar[4]. Bu amaçla bir kimyasal yöntem olan alkali ortamda aktif metali (Al, Zn) elektrokatalizörden uzaklaştırma yöntemi, ucuz ve kolay uygulanabilirdir. Örneğin Solmaz ve ark. (2016) yaptıkları çalışmada NiZn elektrokatalizörünü hazırladıktan sonra Zn'nin elektrokatalizörden uzaklaştırılmasını, 1 gün boyunca \%30'luk $\mathrm{NaOH}$ çözeltisinde bekleterek yapmışlardır. Bu sayede elektrotun yüzey alanının arttığını belirtmişlerdir[11]. Başka bir çalışmada, Crnkovic ve ark. (2004), Ni-Fe-Mo-Zn elektrokatalizörünü hazırlayarak, elektrokatalizörün yüzey alanını arttırmak için $80^{\circ} \mathrm{C}$ 'de, 4 saat boyunca $\% 28$ lik $\mathrm{KOH}$ çözeltisinde bekletmişler ve daha geniş yüzey alanlı elektrokatalizör elde etmişlerdir[12].

$\mathrm{Bu}$ çalışmada Bakır $(\mathrm{Cu})$ elektrot, ince bir Ni filmi ile kaplanmış daha sonra ikili $\mathrm{CuZn}$ ile yüzey modifiye edilmiştir. Hazırlanan elektrokatalizör, 1 gün boyunca $\% 30$ luk $\mathrm{NaOH}$ çözeltisinde bekletilerek aktif Zn'nin uzaklaştırılması sağlanmıştır. Böylelikle elektrokatalizörün yüzey alanı genişletilmiştir. Elektrokatalizörün HER davranışı ise 1,0 M KOH çözeltisinde incelenmiştir. Kıyaslamak amacıyla bakır kaplı bakır $(\mathrm{Cu} / \mathrm{Cu})$ elektrotunda HER davranışı aynı ortamda incelenmiştir.

\section{Materyal ve Yöntem}

Çalışma elektrotlarında malzeme olarak bakır $(\mathrm{Cu})$ elektrot kullanılmıştır. $\mathrm{Cu}$ elektrot şu şekilde hazırlanmışırı: Silindirik bakır çubuklar (6 mm çapında) $4 \mathrm{~cm}$ uzunluğunda kesilerek bir ucunda iletkenliği sağlamak üzere bakır tel ile tutturularak diğer ucu açıkta kalacak şekilde geri kalan kısım polyester ile tamamen kaplandıktan sonra açık kalan yüzeyin alanı $0,283 \mathrm{~cm}^{2}$ olacak şekilde hazırlanmıştır. Hazırlanan Cu elektrotlardan elektrokimyasal olarak $\mathrm{Cu} / \mathrm{Cu}$ ve $\mathrm{Cu} / \mathrm{Ni} / \mathrm{CuZn}$ olmak üzere iki farklı yüzey elde edilmiştir.

İlki $\mathrm{Cu}$ banyosunda elektrokimyasal olarak oluşturulan $\mathrm{Cu}$ kaplı $\mathrm{Cu}(\mathrm{Cu} / \mathrm{Cu})$ yüzeydir. Bu banyoda \%26,67 $\mathrm{CuSO}_{4} .5 \mathrm{H}_{2} \mathrm{O}, \% 1,25 \mathrm{H}_{3} \mathrm{BO}_{3}$ kullanılmıştır.

İkincisi ince bir Ni ile kaplanmış olan $\mathrm{Cu}$ üzerinde oluşturulan $\mathrm{CuZn}(\mathrm{Cu} / \mathrm{Ni} / \mathrm{CuZn})$ yüzeydir. $\mathrm{Cu}$ yüzeyinde elektrokimyasal olarak Ni kaplaması oluşturmak için Nikel banyosu kullanılmıştır. Bileşimi: \%30,00 NiSO $4.6 \mathrm{H}_{2} \mathrm{O}$, $\% 1,00 \mathrm{NiCl}_{2} \cdot 6 \mathrm{H}_{2} \mathrm{O}, \% 1,25 \mathrm{H}_{3} \mathrm{BO}_{3}$. Ni yüzeyinde elektrokimyasal olarak $\mathrm{CuZn}$ oluşturmak için ise $\mathrm{CuZn}$ banyosunun bileşimi \%1,78 $\mathrm{CuSO}_{4} .5 \mathrm{H}_{2} \mathrm{O}, \% 30,70 \mathrm{ZnSO}_{4} .7 \mathrm{H}_{2} \mathrm{O}, \% 5,00 \mathrm{Na}_{3} \mathrm{C}_{6} \mathrm{H}_{5} \mathrm{O}_{7} .2 \mathrm{H}_{2} \mathrm{O}, \% 1,25 \mathrm{H}_{3} \mathrm{BO}_{3}$ şeklindedir.

Bakır elektrot yüzeyinde kaplamaların yapılmasında, elektrokimyasal ölçümlerde ve kararlılık ve dayanıklılık testlerinde geleneksel üç elektrotlu elektrokimyasal sistem kullanılmıştır (Şekil 1). Bu amaçla $2 \mathrm{~cm}^{2}$ yüzey alanına sahip Pt tel karşıt elektrot, hazırlanan elektrotlar çalışma elektrodu olarak ve $\mathrm{AgAgCl}(3 \mathrm{M} \mathrm{KCl})$ elektort ise referans elektrot olarak kullanılmıştır. Bakır elektrot yüzeyinde kaplamaların yapılmasında ve elektrokimyasal ölçümlerde Ivium Vertex Potansiyostat \& Galvanostat-V55600 ölçüm cihazı kullanılmıştır. Kararlılık ve dayanıklılık testlerinde ise Gamry Reference 3000 Potentiostat cihazı kullanılmıştır. $\mathrm{Cu} / \mathrm{Ni} / \mathrm{CuZn}$ elektrotun yüzey alanını genişletmek için, hazırlanan elektrotlar önce 4 saat 1,0 M NaOH çözeltisinde $\mathrm{Zn}$ yavaş bir şekilde uzaklaştırılması için bekletilmiş daha sonra 20 saat süresince $\% 30 \mathrm{NaOH}$ çözeltisine alınarak aktif çinko uzaklaştırılmıştır. Hazırlanan elektrotların HER davranışı 1,0 M KOH çözeltisinde incelenmiştir (Resim 1). CV eğrileri hidrojen ve oksijen çıkışının olduğu potansiyel aralığında $100 \mathrm{mVs}^{-1}$ tarama hızında elde edilmiştir. Yarı logaritmik katodik akım-potansiyel eğrileri $-1,80 \mathrm{~V}$ ile sıfır akım potansiyel aralığında $5 \mathrm{mVs}^{-1}$ tarama hızında yapılmıştır. Kararlılık ve dayanıklılık testleri için kronoamperometri (CA) yöntemi ile CV teknikleri kullanılmıştır. 
$\mathrm{CA}$ eğrisi -1,35 V'ta 5 saat boyunca $\mathrm{Cu} / \mathrm{Ni} / \mathrm{CuZn}$ elektrotunda alınmıştır. $\mathrm{CV}$ deneyleri ise $50 \mathrm{mVs}^{-1}$ tarama hızında 300 döngü alınarak elde edilmiştir. Tüm deneylerde Nuve BS 30 marka su banyosu kullanılmış olup sıcaklık yaklaşık $25^{\circ} C^{\prime}$ ye ayarlanmıştır. Elektrot yüzeyini karakterize etmek için taramalı elektron mikroskop (SEM) (FEI, QUANTA FEG 650), enerji dağılımlı X-Işını (EDX), atomik kuvvet mikroskobu (AFM) (Park systems, NX 10), X-1şını kırınımı (XRD) ve dönüşümlü voltametri (CV) tekniklerinden yararlanılmıştır. Kullanılan tüm kimyasallar analitik saflıkta olup Merck firmasından temin edilmiştir. Her bir elektrokimyasal deneyler en az üç kez tekrarlanmıştır.

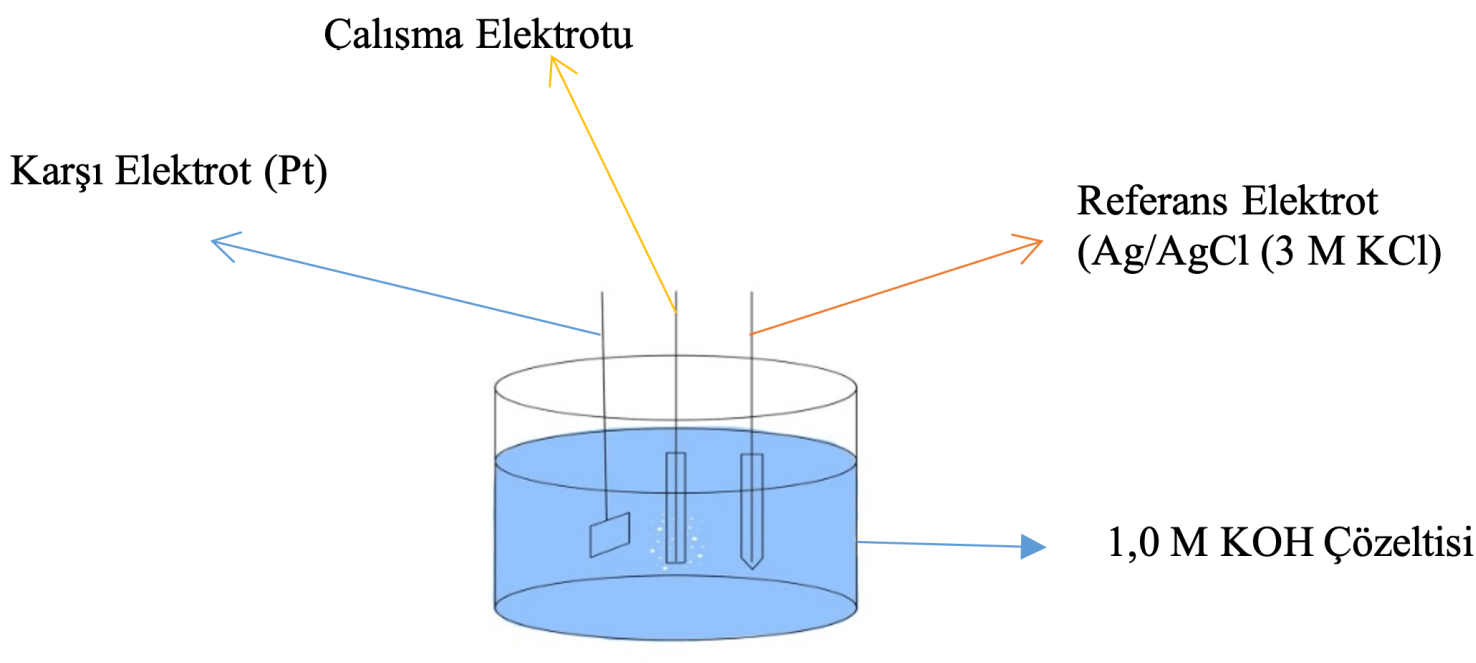

Şekil 1. Üç elektrotlu hücre.

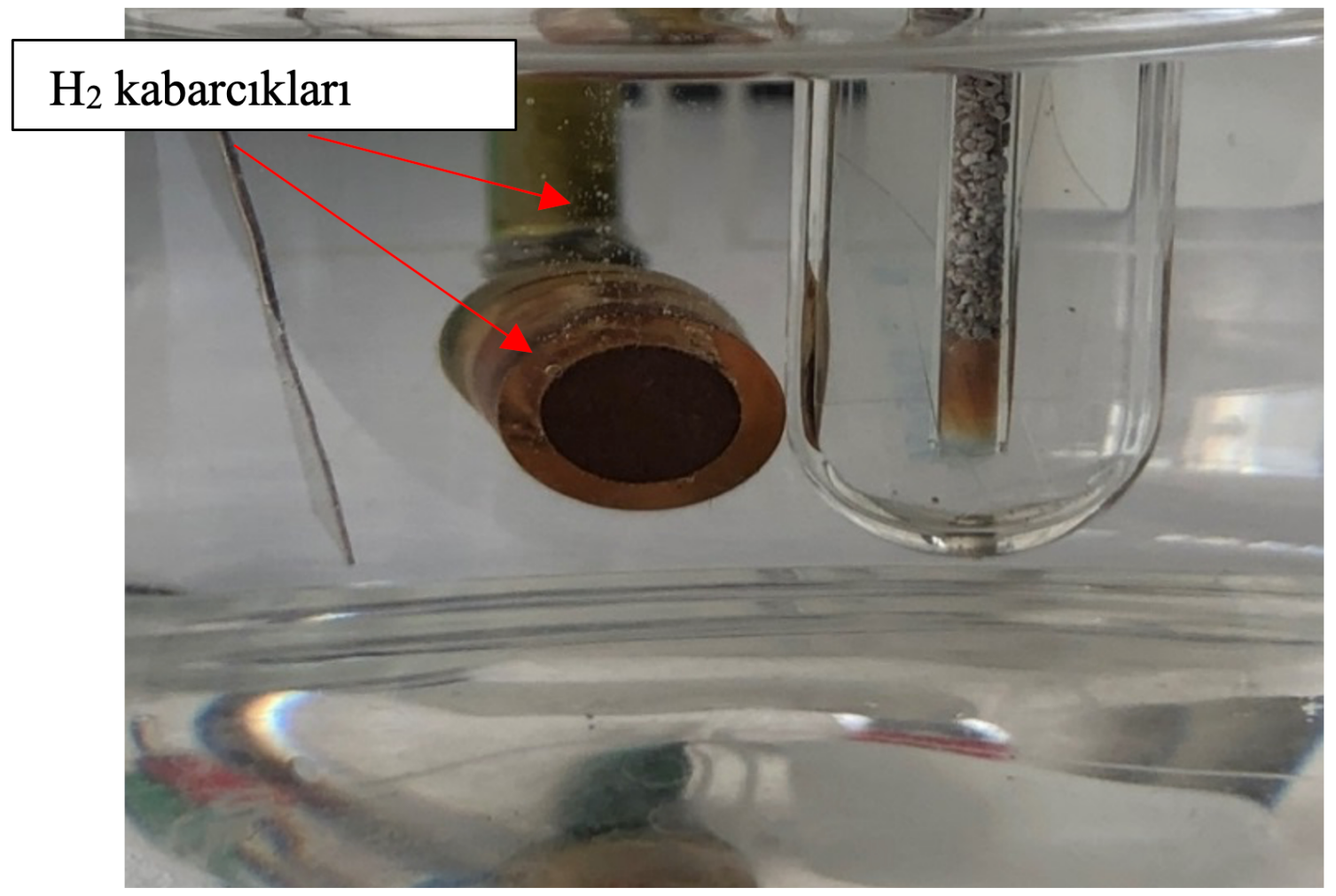

Resim 1. $\mathrm{Cu} / \mathrm{Ni} / \mathrm{CuZn}$ elektrotta 1,0 M KOH çözeltisinde hidrojen gazının oluştuğunu gösteren fotoğraf. 


\section{Bulgular ve Tartışma}

$\mathrm{Cu}$ elektrot yüzeyinde $\mathrm{Cu}$ ve $\mathrm{CuZn}$ tabakalarının oluşumu esnasında morfolojideki değişimleri araştırmak için SEM resimleri çekildi. Şekil 2, Cu ve CuZn yüzeylerinin SEM resimlerini göstermektedir. Şekil 2a ve b'de $\mathrm{Cu} / \mathrm{Cu}$ elektrot yüzeyinin sırasıyla 60 kat ve 10000 kat büyütülmüş resimleri yer almaktadır. Şekil 2c ve d'de ise $\mathrm{Cu} / \mathrm{Ni} / \mathrm{CuZn}$ elektrot yüzeyinin sırasıyla 60 kat ve 10000 kat büyütülmüş resimleri yer almaktadır. Uzak mesafe (Şekil 2a ile c) ve yakın mesafe (Şekil 2b ile d) SEM görüntüleri karşılaştırıldığında iki yüzeyin birbirinden çok faklı olduğu açıkça görülmektedir. 60 kat büyütülmüş SEM resimlerinde CuZn'nun yüzeyinin, $\mathrm{Cu}$ yüzeyinden daha pürüzlü olduğu görülmektedir. $\mathrm{Cu}$ yüzeyi oldukça pürüzsüz görülürken, $\mathrm{CuZn}$ yüzey girinti ve çıkıntılarla kaplıdır. 10000 kat büyütülmüş SEM resimlerinde ise $\mathrm{Cu}$ yüzeyde kristalik tanecikler ile kaplı iken, CuZn yüzey (Şekil 2d) karnabahar görüntüsündedir [13,14]. Buda yüzey alanının arttığını ve aktif merkezlerin çoğaldığını göstermektedir. Görüldüğü gibi $\mathrm{CuZn}$ yüzeyinden Zn'nin uzaklaştırılması yüzey morfolojisini değiştirerek elektrotun yüzey alanının artmasına sebep olmaktadır.

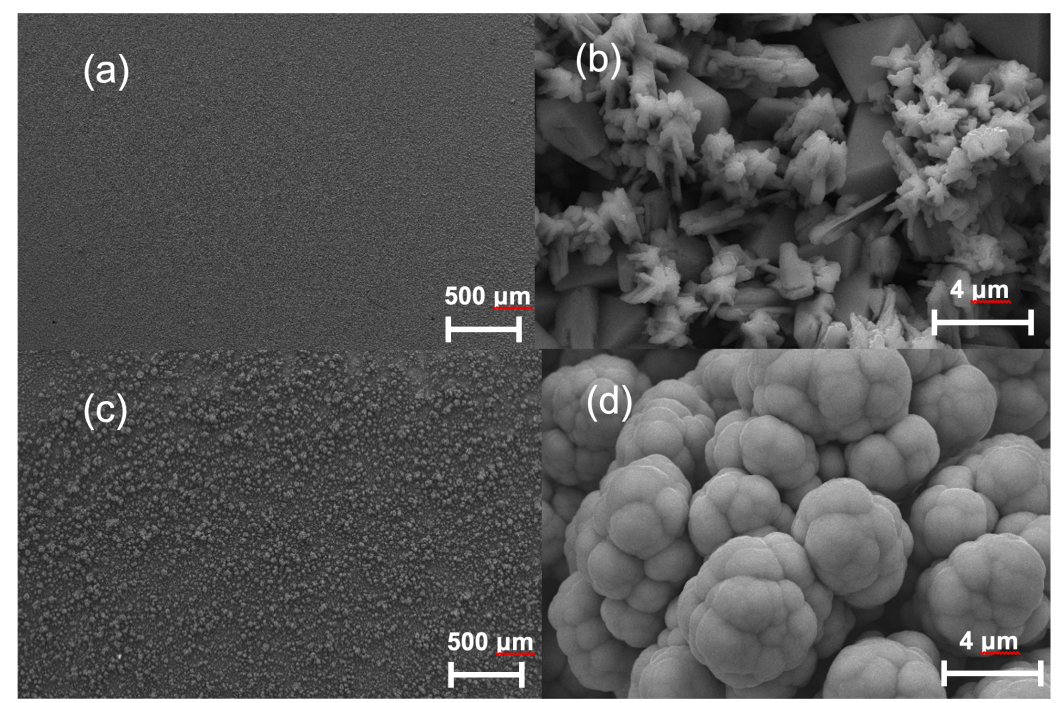

Şekil 2. $\mathrm{Cu} / \mathrm{Cu}(\mathrm{a}: 60 \mathrm{X}$, b: 10 000X) ve $\mathrm{Cu} / \mathrm{Ni} / \mathrm{CuZn}(\mathrm{c}: 60 \mathrm{X}$, d: 10 000X) elektrotların SEM görüntüsü.

$\mathrm{Cu}$ elektrot yüzeyindeki oluşturulan film bileşimleri EDX ile analiz edilmiş ve spektrumlar Şekil 3'de sunulmuştur. $\mathrm{Bu}$ filmlerdeki elementlerin bileşimleri ise yüzdelik olarak Tablo 1'de verildi. Spektrumlarda görüldüğü gibi bakır yüzeyinde oluşturulan filmlerdeki elementlerin karakteristik pikleri açıkça görülmektedir. Tablo 1 incelendiği zaman, $\mathrm{Cu}$ elektrot üzerinde \%82,7 oranında $\mathrm{Cu}$ bulunan film oluştuğu görülmektedir. $\mathrm{Ni} / \mathrm{CuZn}$ filminde $\% 72,24 \mathrm{Cu}, \% 0,67 \mathrm{Ni}$ ve $\% 13,51 \mathrm{Zn}$ bulunmaktadır. Yüzeylerde ayrıca $\mathrm{C}$ ve $\mathrm{O}$ piklerinin de oluştuğu görülmektedir. EDX sonuçlarına göre, yüzeyde $\mathrm{Cu}$ ve $\mathrm{CuZn}$ kaplamalarının başarılı bir şekilde oluşuturulduğu söylenebilir. Aynı zamanda, yüzeyde \%13,51 gibi az bir oranda Zn bulunması, bazik ortamda $\mathrm{Zn}$ uzaklaştığında yüzeyde HER için geniş bir alanın oluşacağının işaretidir.

Tablo 1. Elektrotların EDX sonuçları

\begin{tabular}{lccccc}
\hline \multirow{2}{*}{ Elektrot } & \multicolumn{5}{c}{ Atomik\% } \\
\cline { 2 - 6 } & $\mathrm{Cu}$ & $\mathrm{Ni}$ & $\mathrm{Zn}$ & $\mathrm{C}$ & $\mathrm{O}$ \\
\hline $\mathrm{Cu} / \mathrm{Cu}$ & 82.7 & - & - & 10.86 & 6.44 \\
& & & & & \\
\hline $\mathrm{Cu} / \mathrm{Ni} / \mathrm{CuZn}$ & 72.24 & 0.67 & 13.51 & 10.57 & 3.02 \\
\hline
\end{tabular}



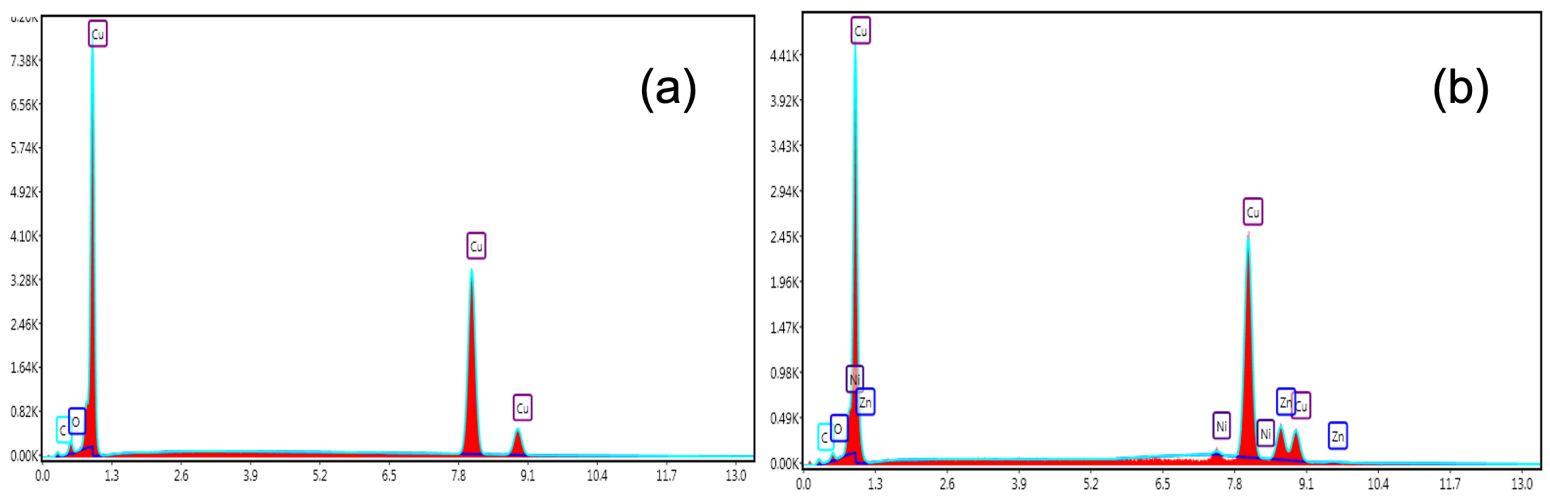

Şekil 3. $\mathrm{Cu} / \mathrm{Cu}(\mathrm{a})$ ve $\mathrm{Cu} / \mathrm{Ni} / \mathrm{CuZn}$ (b) elektrotların EDX spektrumları.

AFM elektrot yüzeyinin mikroyapısının karakterize edilmesinde önemli bir yöntemdir[15]. Dolayısıyla $\mathrm{Cu} / \mathrm{Cu}$ ve $\mathrm{Cu} / \mathrm{Ni} / \mathrm{CuZn}$ elektrotların üç boyutlu (3D) AFM görüntüleri Şekil 4’te verilmektedir. Şekilde görüldüğ̈ü gibi $\mathrm{Cu} / \mathrm{Cu}$ ile $\mathrm{Cu} / \mathrm{Ni} / \mathrm{CuZn}$ elektrotların 3D AFM görüntüleri birbirinden farklıdır. $\mathrm{Cu} / \mathrm{Cu}$ elektrot yüzeyinde geniş tepeler oluşurken SEM görüntülerindeki kristal yapıya işaret edebilir. $\mathrm{Cu} / \mathrm{Ni} / \mathrm{CuZn}$ elektrot yüzeyinde ise küresel taneciklerin oluşturduğu girinti ve çıkıntılar görülmektedir. Bu küresel tanecikler yine SEM görüntülerinde de görülmektedir. Her iki yüzey oldukça pürüzlü olup, bu pürüzlü yapı HER aktiviteyi arttırabilir.
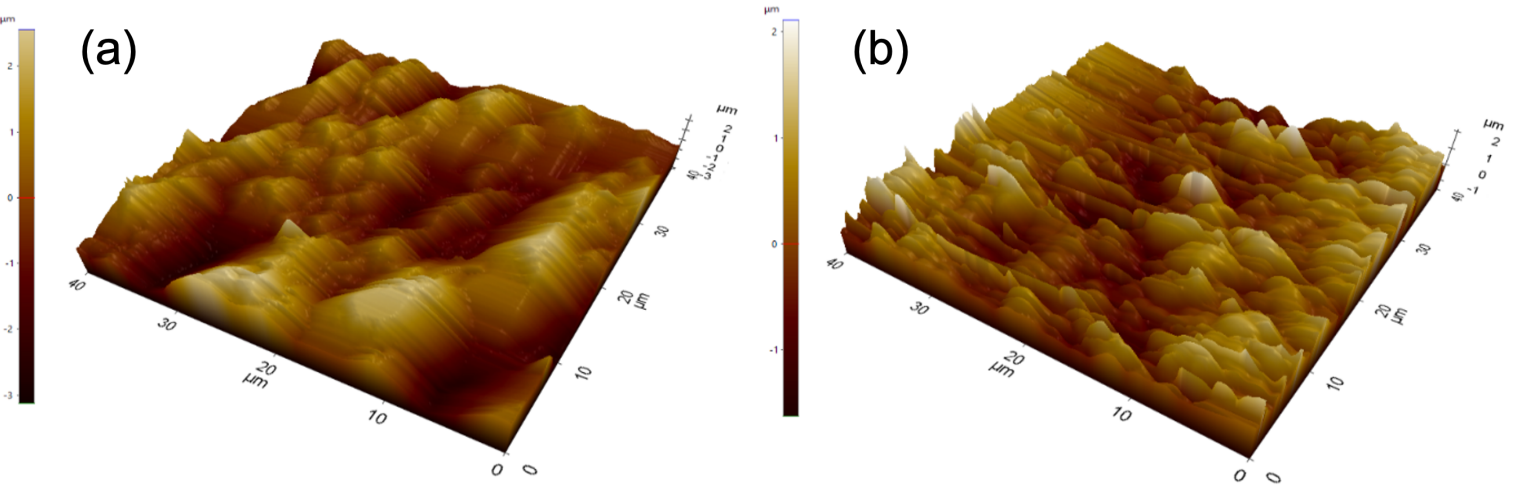

Şekil 4. $\mathrm{Cu} / \mathrm{Cu}$ (a) ve $\mathrm{Cu} / \mathrm{Ni} / \mathrm{CuZn}$ (b) elektrotların üç boyutlu (3D) AFM görüntüleri.

$\mathrm{Cu} / \mathrm{Cu}$ ve $\mathrm{Cu} / \mathrm{Ni} / \mathrm{CuZn}$ elektrotların kristal yapılarını açıklayabilmek için XRD analizleri yapılmış olup, ilgili spektrum Şekil 5'de verilmiştir. Şekil 5a'ya bakıldığında $43,3^{\circ}, 50,4^{\circ}$ ve $74,1^{\circ}$ de açığa çıkan pikler sırasıyla $\mathrm{Cu}(111), \mathrm{Cu}(200)$ ve $\mathrm{Cu}(220)$ yüzey merkezli kübik (fcc) (Referans no: 98-005-3247) yapılarını işaret etmektedir. Şekil 5 b incelediğinde ise yaklaşık $43^{\circ}, 50^{\circ}$ ve $74^{\circ}$ dolaylarında açığa çıkan pikler Ni metali için Ni(111), Ni(020) ve Ni(220) yüzey merkezli kübik (fcc) (Referans no: 96-901-3034) yapılarına karş1lık gelmektedir. Cu metali için ise $\mathrm{Cu} / \mathrm{Cu}$ elektrotuna karşılık gelen pikler ile hemen hemen aynıdır. $\mathrm{Cu}$ ve Ni metallerinin piklerine ek olarak $43^{\circ}$, $76^{\circ}$ ve $83^{\circ}$ kırınım pikleri ise $\mathrm{Zn}(101), \mathrm{Zn}(400)$ ve $\mathrm{Zn}(002)$ hekzagonal yapıya (hcp) (Referans no: 96-901-1600) işaret etmektedir. XRD ile elde edilen sonuçlar EDX sonuçlarını desteklemektedir.

$\mathrm{Cu} / \mathrm{Cu}$ ve $\mathrm{Cu} / \mathrm{Ni} / \mathrm{CuZn}$ elektrotların karakterizasyonu SEM, EDX, AFM ve XRD ile yapıldıktan sonra ayrıca $\mathrm{CV}$ yöntemiyle de karakterizasyon yapılmıştır. Şekil 6a'daki $\mathrm{Cu} / \mathrm{Cu}$ elektrotun $\mathrm{CV}$ eğrisi incelendiğinde tipik bakırın pikleri ortaya çıkmıştır. İleri yönlü taramada 3, geri yönlü taramada 3 olmak üzere toplam 6 pik ortaya çıkmıştır. Bu piklerden -0,414 V'ta $\mathrm{Cu} / \mathrm{Cu}^{+}\left[-0,066 \mathrm{~V}\right.$ 'ta $\mathrm{Cu} / \mathrm{Cu}^{++}$ve $0,604 \mathrm{~V}$ 'ta ise $\mathrm{Cu}^{++} / \mathrm{Cu}^{+++}$geçişlerdir[16-19]. Geri yönlü taramada ise $0,519 \mathrm{~V}$ 'ta $\mathrm{Cu}^{+++} / \mathrm{Cu}^{++}$ye, $-0,652 \mathrm{~V}^{\prime}$ ta $\mathrm{Cu}^{++} / \mathrm{Cu}^{\prime}$ ya ve $-1,01 \mathrm{~V}$ 'ta ki ise $\mathrm{Cu}^{+} / \mathrm{Cu}^{\prime}$ ya geçiş piklerini ifade etmektedir[20-24]. $\mathrm{Cu} / \mathrm{Ni} / \mathrm{CuZn}$ elektrotun $\mathrm{CV}$ eğrisine bakıldığ 1 zaman benzer piklerin oluştuğu söylenebilir. Fakat Zn'nin elektrottan uzaklaştırılmasıyla pikler genişleyerek akım değerlerinin artışına sebep olmuştur. Bakırın piklerine ek olarak çinkonun piklerinin de gözüktüğü söylenebilir. 


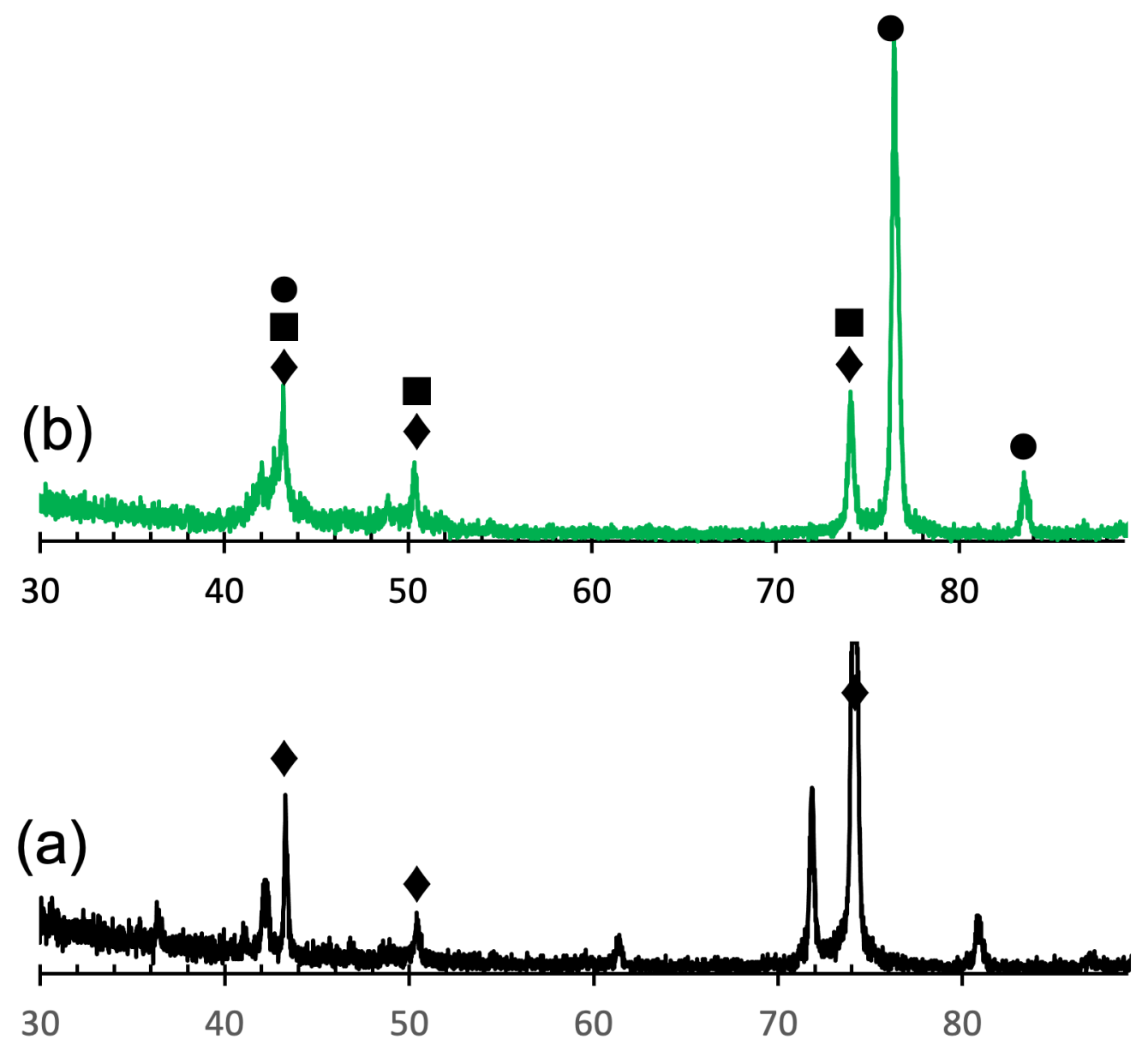

Şekil 5. (a) $\mathrm{Cu} / \mathrm{Cu}$ ve (b) $\mathrm{Cu} / \mathrm{Ni} / \mathrm{CuZn}$ elektrotların $\mathrm{X}$-ışını kırınım yöntemiyle elde edilen spektrumları $(\bullet: \mathrm{Cu}, \bullet: \mathrm{Zn}, \mathbf{\mathbf { a }}: \mathrm{Ni})$

Şekil 6b'de her iki elektrot için hidrojen adsorpsiyon bölgesinin büyütülmüş hali görülmektedir. Şekil 6'da görüldüğü gibi $\mathrm{Cu} / \mathrm{Ni} / \mathrm{CuZn}$ elektrotun hidrojen çıkışının başladığı potansiyeli Tablo 2'de $-1,434 \mathrm{~V}$ iken, $\mathrm{Cu} / \mathrm{Cu}$ için bu değer -1,654 V'tur. Dolayısıyla $\mathrm{Cu} / \mathrm{Ni} / \mathrm{CuZn}$ elektrotunda daha düşük bir hidrojen aşırı gerilimi mevcuttur bu da, bu elektrotun katalitik etkinliğinin daha yüksek olduğu anlamına gelmektedir. Aşağıda $\mathrm{Cu} / \mathrm{Cu}$ için ileri ve geri yönlü taramada oluşan reaksiyonlar verilmiştir.

$$
\begin{aligned}
& \mathrm{Cu}+\mathrm{OH}^{-} \rightarrow \mathrm{CuOH}+\mathrm{e}^{-} \\
& 2 \mathrm{CuOH} \leftrightarrow \mathrm{Cu}_{2} \mathrm{O}+\mathrm{H}_{2} \mathrm{O} \\
& \mathrm{Cu}+2 \mathrm{OH}^{-} \rightarrow \mathrm{Cu}(\mathrm{OH})_{2}+2 \mathrm{e}^{-} \\
& \mathrm{Cu}_{2} \mathrm{O}+\mathrm{H}_{2} \mathrm{O}+2 \mathrm{OH}^{-} \rightarrow 2 \mathrm{Cu}(\mathrm{OH})_{2}+2 \mathrm{e}^{--} \\
& \mathrm{Cu}(\mathrm{OH})_{2} \leftrightarrow \mathrm{CuO}+\mathrm{H}_{2} \mathrm{O} \\
& \mathrm{CuO}+\mathrm{OH}^{-} \leftrightarrow \mathrm{CuOOH}+\mathrm{e}^{-} \mathrm{H}_{2} \mathrm{O}
\end{aligned}
$$


Tablo 2. Katodik akım-potansiyel ve CV eğrilerinden elde edilen elektrokimyasal parametreler.

\begin{tabular}{llllll}
\hline Elektrot & $-\eta_{50}$ & $j-250$ & $j_{0}$ & $-b_{c}$ & $E_{\text {çıkş } H_{2}}$ \\
& $\mathrm{~V}$ & $\mathrm{~mA} \mathrm{~cm}^{-2}$ & $\mathrm{~mA} \mathrm{~cm}^{-2}$ & $\mathrm{mV} \mathrm{dec}^{-1}$ & $\mathrm{~V}$ \\
\hline $\mathrm{Cu} / \mathrm{Cu}$ & 0,914 & 0,105 & 0,043 & 201 & $-1,654$ \\
$\mathrm{Cu} / \mathrm{Ni} / \mathrm{CuZn}$ & 0,326 & 20,462 & 0,309 & 110 & $-1,434$ \\
\hline
\end{tabular}
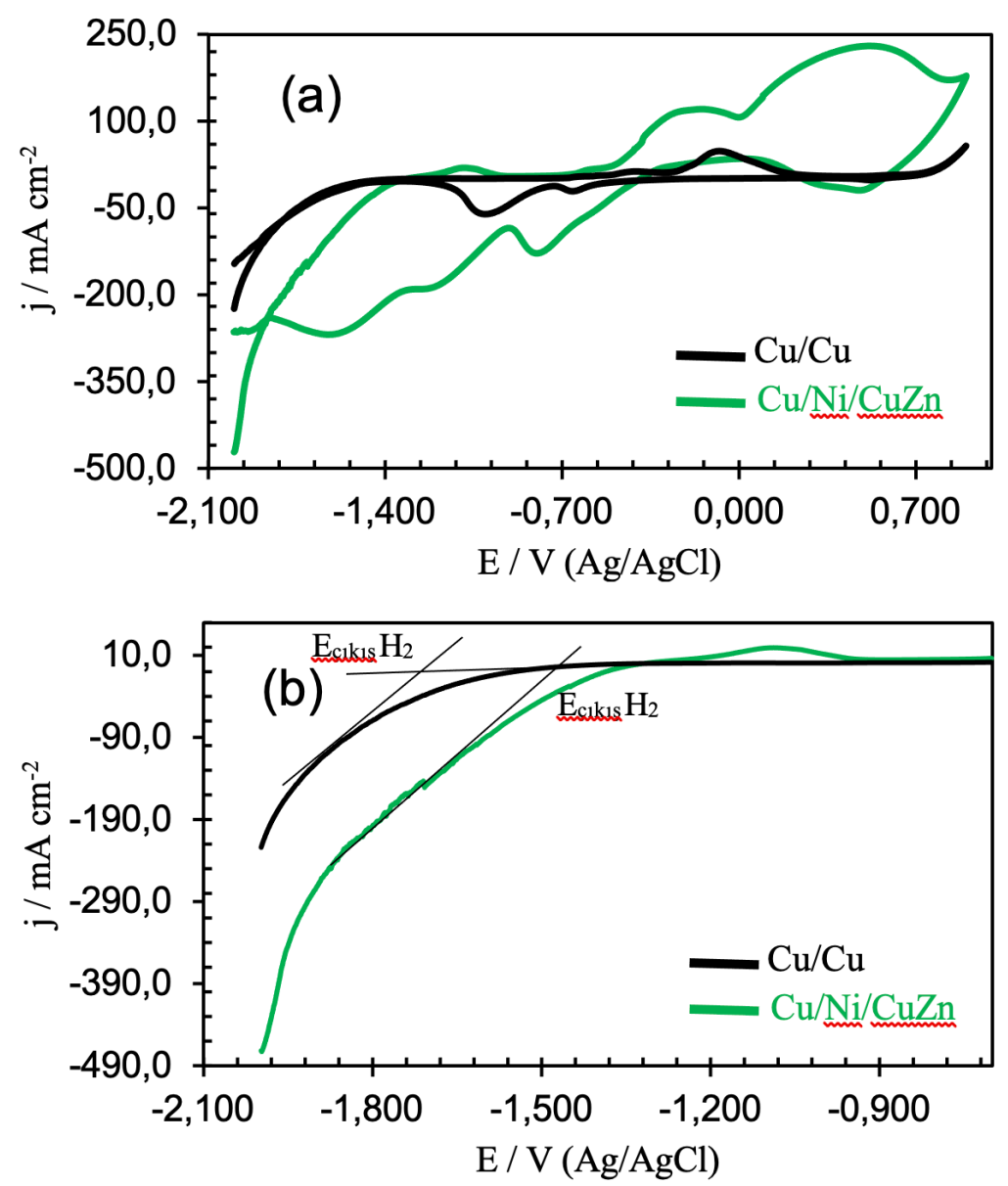

Şekil 6. a: $\mathrm{Cu} / \mathrm{Cu}$ ve $\mathrm{Cu} / \mathrm{Ni} / \mathrm{CuZn}$ elektrotların 1,0 M KOH çözeltisindeki dönüşümlü voltamogramları (Tarama hızı: $100 \mathrm{mV} \mathrm{s}^{-1}$ ). b: CV eğrilerinin hidrojen adsorpsiyon bölgesi.

$\mathrm{Cu} / \mathrm{Cu}$ ve $\mathrm{Cu} / \mathrm{Ni} / \mathrm{CuZn}$ elektrotların HER performansını ölçmek için yarı logaritmik akım-potansiyel eğrileri alınmış ve Şekil 7a'da ve ayrıca her iki elektrot için Tafel eğrileri Şekil 7b'de verilmiştir. Şekil 7a'ya göre yük değişimi akım yoğunluğu $\left(j_{o}\right)$ Tafel ekstrapolasyon yöntemiyle hesaplanmış ve Table 2'de verilmektedir. Bunun dışında Tablo 2'de $j_{-250}-250 \mathrm{mV}$ 'taki akım yoğunluğu değerini ve $-\eta_{50}$ ise $50 \mathrm{~mA} \mathrm{~cm}{ }^{-2}$ akım yoğunluğundaki aşırı gerilimi göstermektedir. Elektrotların Tafel eğimleri ise, Şekil 7b'deki Tafel eğrilerindeki doğrusal kısmın eğimi (Eşitlik 7) hesaplanarak bulunmuştur. Bu parametrelerden yola çıkarak hangi elektrotun HER yönünden daha etkin olduğuna karar verilebilir [25,26].

$\eta=\mathrm{a}+b \log j$ 
Burada $\eta$ aşırı gerilimi (V), $b$ katodik Tafel eğimini $\left(\mathrm{mV} \mathrm{dec}^{-1}\right)$ ve $j\left(\mathrm{~mA} \mathrm{~cm}^{-2}\right)$ 'de akım yoğunluğunu göstermektedir. Şekilde görüldüğü gibi $\mathrm{Cu} / \mathrm{Ni} / \mathrm{CuZn}$ elektrotun katodik akım-potansiyel eğrisi $\mathrm{Cu} / \mathrm{Cu}$ elektrotundan farklı bir yapı sergilemektedir. HER potansiyeli daha negatif değerlere kayarak aşırı gerilim düşmüş ve daha erken potansiyellerde hidrojen çıkışı olmuştur. Tablo 2'ye göre $j_{o}$ kıyaslandığında yaklaşık on katlık bir artı̧̧ ile $0,043 \mathrm{~mA} \mathrm{~cm}^{-2}$, den, $0,309 \mathrm{~mA} \mathrm{~cm}^{-2}$ ye, $j_{-250}$ değeri ise oldukça yükselirken, aynı şekilde $50 \mathrm{~mA} \mathrm{~cm}^{-2}$ akım yoğunluğundaki aşırı gerilimi $\left(-\eta_{50}\right)$ ise oldukça düşmüştür. HER performansını ölçmek ve HER mekanizmasını belirlemek için Tafel eğimlerinin hesaplanması ve kıyaslanması gereklidir. Yüksek performanslı elektrotların Tafel eğimlerinin genelde düşük olması istenir[27]. Tablo 2'de görüldüğü gibi $\mathrm{Cu} / \mathrm{Ni} / \mathrm{CuZn}$ elektrotun Tafel eğimi $110 \mathrm{mV} \mathrm{dec}{ }^{-1}, \mathrm{Cu} / \mathrm{Cu}$ elektrotunkisi ise $201 \mathrm{mV} \mathrm{dec}^{-1}$ olarak ölçülmüştür. Tafel eğiminin düşük olması $\mathrm{Cu} / \mathrm{Ni} / \mathrm{CuZn}$ elektrotun HER açısından daha etkin bir elektrot olduğunu göstermektedir. $\mathrm{Cu} / \mathrm{Ni} / \mathrm{CuZn}$ elektrotun Tafel eğimi $120 \mathrm{mV} \mathrm{dec}^{-1}$ 'e yakın olduğu için HER'un mekanizması Volmer basamağı üzerinden ilerlediğini gösterir. Ayrıca yukarıda hesaplanan diğer parametreler, $\mathrm{Cu} / \mathrm{Ni} / \mathrm{CuZn}$ elektrotunun suyun ayrıştırılmasıyla hidrojen üretimi esnasında oldukça etkili bir elektrokatalizör olduğunu kanıtlar. $\mathrm{Cu} / \mathrm{Ni} / \mathrm{CuZn}$ elektrotun yüksek katalitik etkinliği $\mathrm{Cu}$ ve $\mathrm{Zn}$ metallerinin sinerjistik etkileşimine, Zn'nin kaplamadan uzaklaştırılmasıyla artan yüzey alanına (SEM görüntülerine göre) ve alt tabakadaki Ni'nin katalitik etkisine bağlanabilir[28].
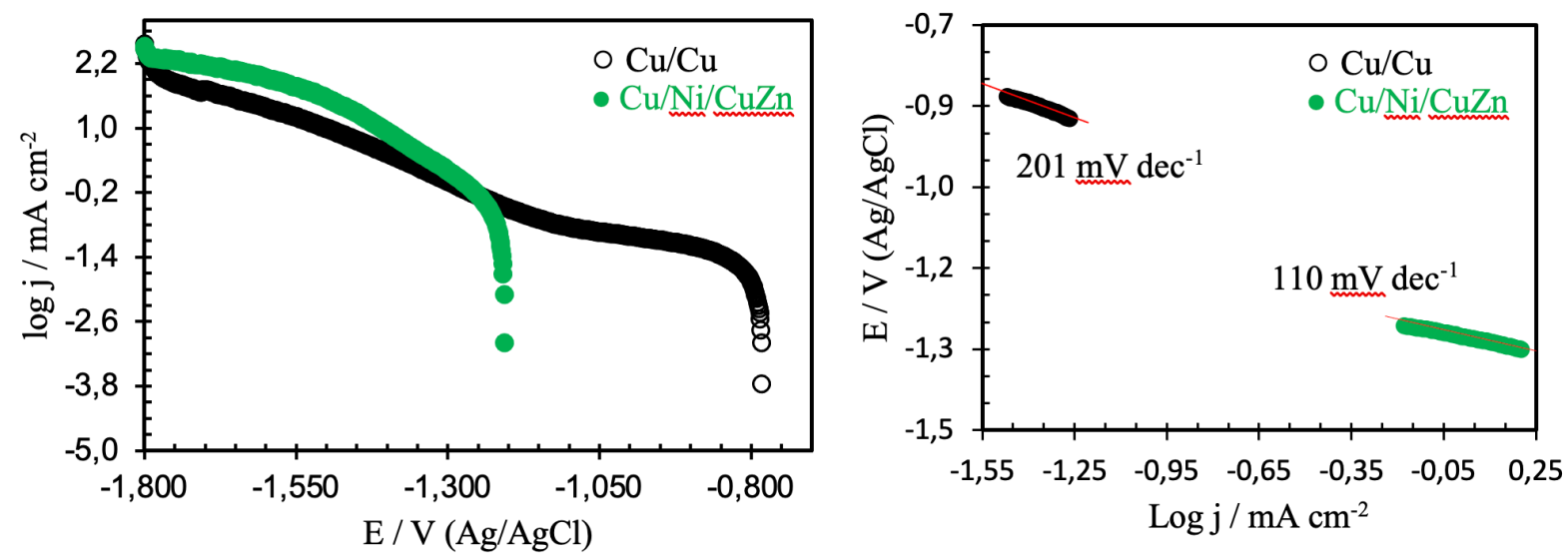

Şekil 7. $\mathrm{Cu} / \mathrm{Cu}$ ve $\mathrm{Cu} / \mathrm{Ni} / \mathrm{CuZn}$ elektrotların 1,0 M KOH çözeltisindeki katodik akım-potansiyel eğrileri (a) ve Tafel eğrileri (b).

$\mathrm{Cu} / \mathrm{Ni} / \mathrm{CuZn}$ elektrotun HER etkinliğinin literatür ile kıyaslaması Tablo 3' de verilmiştir. Literatürde çoğunlukla Pt bazlı elektrotlara alternatif olarak Nikel bazlı elektrotlar gösterilir. Nikelin ikili ve üçlü diğer metaller ile kaplaması oluşturularak yapılan çalışmalar oldukça fazladır. Bu çalışmada hazırlanan $\mathrm{Cu} / \mathrm{Ni} / \mathrm{CuZn}$ elektrot Tabloda verilen bazı ikili Nikel içeren kaplamalar ile kıyaslaması yapılmıştır. Görüldüğü gibi bu çalışmada hazırlanan $\mathrm{Cu} / \mathrm{Ni} / \mathrm{CuZn}$ elektrot, diğer elektrotlardan daha etkindir. Bunun dışında, bilineceği gibi hazırlanan üçlü kaplamalar sahip olduğu geniş yüzey alan nedeniyle çoğunlukla ikili kaplamalardan daha etkin çıkmaktadır. $\mathrm{Cu} / \mathrm{Ni} / \mathrm{CuZn}$ elektrotun HER etkinliği Tabloda verilen üçlü kaplamalar ile kıyaslandığında ise etkinliğin daha düşük olduğu söylenebilir.

Elektrotların katalitik etkinliğinin belirlenmesinin dışında, katalitik etkinliği yüksek olan elektrotun bazik ortamda pratik uygulamalar için dayanıklı ve kararlı olması da istenir. Bu amaçla genellikle kronoamperometri ve dönüşümlü voltametri yöntemleri kullanılır[38]. Katalitik etkinliği yüksek $\mathrm{Cu} / \mathrm{Ni} / \mathrm{CuZn}$ elektrotunda zamanla kararlılık ve dayanıklılık testi yapılmış ve ilgili şekiller Şekil 8'de verilmektedir. Şekil 8a'da Cu/Ni/CuZn elektrotun 5 saat boyunca 1,0 M KOH çc̈zeltisindeki kronoamperometri eğrisi verilmektedir. Kıyaslamak için $\mathrm{Cu} / \mathrm{Cu}$ elektrotunda eğrisi aynı ortamda alınmıştır. $\mathrm{Cu} / \mathrm{Ni} / \mathrm{CuZn}$ elektrotun katalitik etkinliği yüksek olduğu için akım değerleri diğer elektrottan daha yüksek değerlerdedir. Görüldüğü gibi eğri, başlangıç zamanında bir miktar düşmüş ve daha sonra kararlı hale gelmiştir. 5 saatin sonunda $\mathrm{Cu} / \mathrm{Ni} / \mathrm{CuZn}$ elektrotun yüzeydeki değişimini incelemek için SEM görüntüsü alınmış ve Şekil $8 b$ 'de verilmektedir. SEM görüntüsüne göre yüzey 5 saatin sonunda karnabahar yapıdan kristal yapıya dönmüş, yüzeyin gözenekli hali burada da görülmektedir. Kronoamperometriye ek olarak CV yöntemiyle elektrotta 300 döngü alınmış ve 1. ile 300. döngüler Şekil 8c'de verilmektedir. Şekil 8c'ye göre döngüler arasında ihmal edilebilir bir potansiyel kayma mevcuttur. Hem kronoamperometri hem de $\mathrm{CV}$ yöntemiyle alınan sonuçlara göre $\mathrm{Cu} / \mathrm{Ni} / \mathrm{CuZn}$ elektrot bazik ortamda zamanla kararlı ve dayanıklı bir yapı sergilemiştir. Bunun sebebi, CuZn kaplamasının Ni yüzeyindeki yapısına ve CuZn kaplaması ile Ni arasındaki güçlü etkileşimine dayanabilir[39]. 
Tablo 3. $\mathrm{Cu} / \mathrm{Ni} / \mathrm{CuZn}$ elektrotun elektrokatalitik etkinliğinin literatürle kıyaslanması.

\begin{tabular}{|c|c|c|c|c|c|}
\hline Elektrot & $-\eta(\mathrm{mV})$ & $j_{o}\left(\mathrm{~mA} \mathrm{~cm}^{-2}\right)$ & Çözelti & $-b_{c}\left(\mathrm{mV} \mathrm{dec}{ }^{-1}\right)$ & Ref \\
\hline \multirow{3}{*}{$\mathrm{CuZn}$} & $205 @ 10 \mathrm{~mA} \mathrm{~cm}^{-2}$ & & & & \multirow{3}{*}{$\begin{array}{l}\mathrm{Bu} \\
\text { çalışma }\end{array}$} \\
\hline & $326 @ 50 \mathrm{~mA} \mathrm{~cm}^{-2}$ & $0,309 @ 25^{\circ} \mathrm{C}$ & $1 \mathrm{M} \mathrm{KOH}$ & 110 & \\
\hline & 482@135mA cm-2 & & & & \\
\hline $\mathrm{Y}_{1} \mathrm{~g} ı \mathrm{n} \mathrm{NiCu}$ & - & 0,04 & $6 \mathrm{M} \mathrm{KOH}$ & 149 & [29] \\
\hline $\mathrm{NiCu}$ & $229 @ 10 \mathrm{~mA} \mathrm{~cm}^{-2}$ & 0,096 & $1 \mathrm{M} \mathrm{KOH}$ & 116 & {$[30]$} \\
\hline $\mathrm{NiCo}$ & - & $3,54 \times 10^{-4}$ & $1 \mathrm{M} \mathrm{KOH}$ & 127 & [31] \\
\hline $\mathrm{Ni}-\mathrm{Co} / \mathrm{NF}$ & $301 @ 10 \mathrm{~mA} \mathrm{~cm}^{-2}$ & 0,176 & $1 \mathrm{M} \mathrm{KOH}$ & 169 & [32] \\
\hline NiMo & - & 0,00239 & $1 \mathrm{M} \mathrm{KOH}$ & 115 & {$[33]$} \\
\hline $\mathrm{NiCo}$ & - & 0,0072 & $1 \mathrm{M} \mathrm{KOH}$ & 125 & [34] \\
\hline ZnCoMo & - & $0,0012 @ 30{ }^{\circ} \mathrm{C}$ & $6 \mathrm{M} \mathrm{KOH}$ & 109 & {$[35]$} \\
\hline CoWZn & $1,672 @ 50 \mathrm{~mA} \mathrm{~cm}^{-2}$ & 0,076 & $1 \mathrm{M} \mathrm{KOH}$ & 135 & {$[36]$} \\
\hline $\mathrm{NiFeZn}$ & $162 @ 135 \mathrm{~mA} \mathrm{~cm}^{-2}$ & 0,066 & $1 \mathrm{M} \mathrm{NaOH}$ & 52 & [37] \\
\hline
\end{tabular}
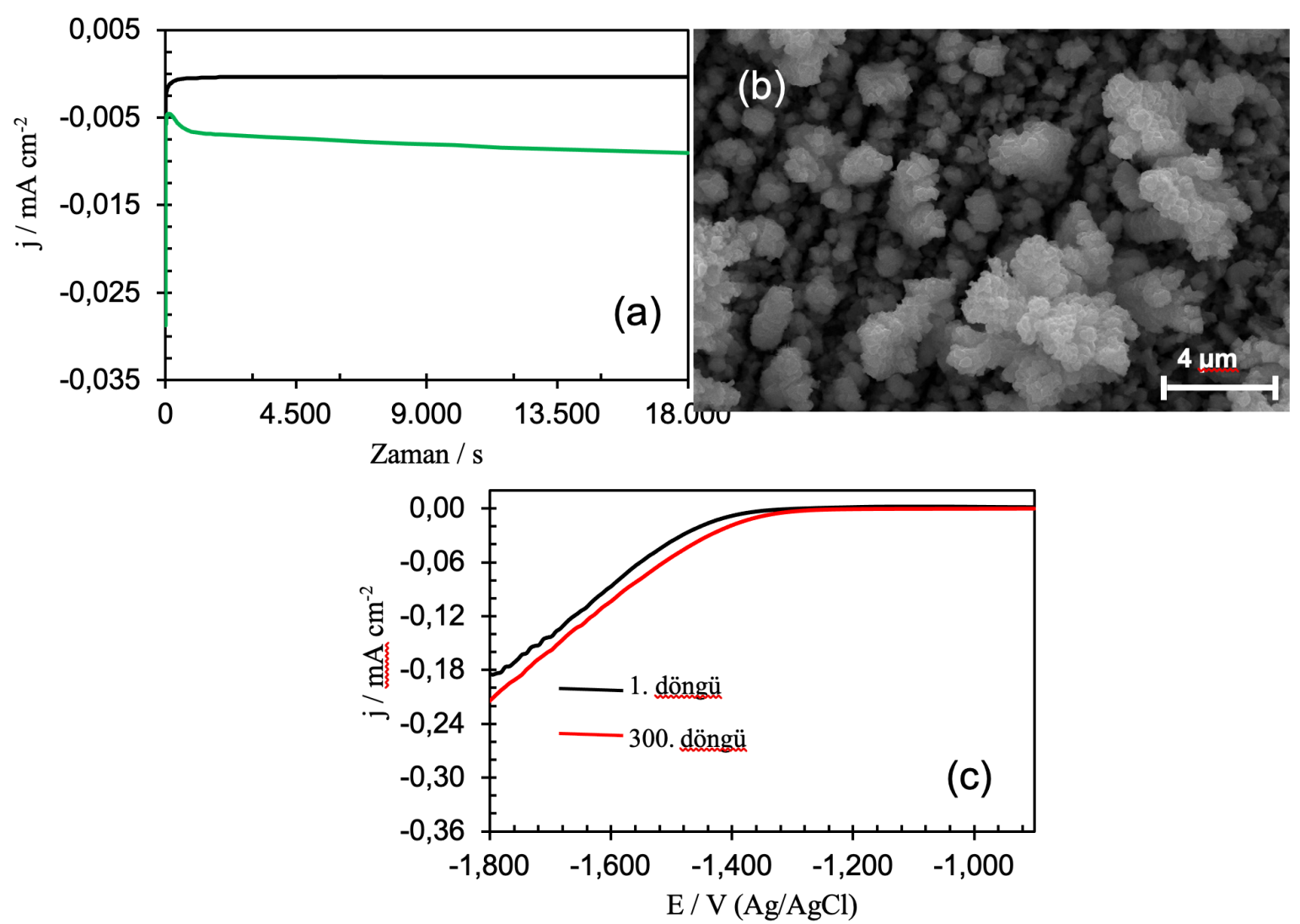

Şekil 8. a: $\mathrm{Cu} / \mathrm{Cu}$ ve $\mathrm{Cu} / \mathrm{Ni} / \mathrm{CuZn}$ elektrotların 1,0 M KOH çözeltisindeki kronoamperometri eğrileri. b: $\mathrm{Cu} / \mathrm{Ni} / \mathrm{CuZn}$ elektrotunun kronoamperometri ölçümünden sonraki SEM görüntüsü (Büyütme: $20000 \mathrm{X}$ ). c: $\mathrm{Cu} / \mathrm{Ni} / \mathrm{CuZn}$ elektrotunun 1,0 M KOH çözeltisindeki 1. ve 300. döngüden sonra, $50 \mathrm{mV} \mathrm{s}^{-1}$ tarama hızında elde edilen dönüşümlü voltamogramları. 


\section{Sonuçlar}

Özet olarak, CuZn elektrot başarılı bir şekilde bakır elektrot yüzeyinde sentezlendi. Bakır elektrotun korozyon dayanımını arttırmak için bakır yüzeyi ince bir Ni filmi ile kaplanmıştır. Kaplamadan aktif Zn metalinin kısmen uzaklaştırılması SEM görüntülerine göre yüzeyin daha gözenekli hale gelmesini sağlayarak HER için aktif merkezlerin sayısını artırmıștır. EDX spektrumuna ve CV eğrilerine göre CuZn elektrotta ilgili metallerin karakteristik pikleri elde edilmiştir. $\mathrm{Bu}$ da kaplamanın $\mathrm{Cu} / \mathrm{Ni}$ yüzeyinde başarılı bir şekilde oluşturulduğunu göstermektedir. AFM görüntülerinden CuZn kaplamanın yüzey alanının daha fazla olduğu görülmüștür. Elektrokimyasal ölçümlere göre $\mathrm{Cu} / \mathrm{Cu}$ elektrota kıyasla $\mathrm{Cu} / \mathrm{Ni} / \mathrm{CuZn}$ elektrotta daha yüksek yük değişimi akım yoğunluğu, daha düşük HER aşırı gerilimi ve Tafel eğimi ve sabit akım yoğunluklarında daha düşük aşırı gerilimler oluşmuştur. Zn metalinin kısmi olarak kaplamadan uzaklaştırılması elektrot yüzey alanını arttırmış, Zn ve $\mathrm{Cu}$ arasındaki sinerjistik etki nedeniyle farkedilebilir derecede HER etkinlik artırmıştır. Kararlılık ve dayanıklılık testlerine göre ise $\mathrm{Cu} / \mathrm{Ni} / \mathrm{CuZn}$ elektrot çalışılan ortamda nikel kaplama ile CuZn'nin kuvvetli etkileşimi nedeniyle yüksek performans sergilemiş̧ir. Bu sonuçlardan yola çıkılarak $\mathrm{Cu} / \mathrm{Ni} / \mathrm{CuZn}$ elektrotta $\mathrm{Ni}$ kaplı elektrotlar ile kıyaslanabilir ölçüde yüksek etkinliğin oluştuğu söylenebilir. Bu nedenle ticari elektroliz sistemleri için $\mathrm{Cu} / \mathrm{Ni} / \mathrm{CuZn}$ elektrot, $\mathrm{Ni}$ kaplı elektrotlara alternatif bir elektrot olarak önerilebilir.

\section{Teșekkür}

Bu çalışma MAÜ.BAP.20.SBF.001 nolu projesi ile Mardin Artuklu Üniversitesi, Bilimsel Araştırma Projeleri Koordinasyon Birimi tarafından desteklenmiştir. Mardin Artuklu Üniversitesi, Bilimsel Araştırma Projeleri Koordinasyon Birimine teşekkür ederim. Şırnak Üniversitesi öğretim üyesi Doç. Dr. Ali Döner’e rehberliği için müteşekkirim.

\section{Kaynaklar}

[1] Wang J, Kong H, Zhang J, Hao Y, Shao Z, Ciucci F. Carbon based electrocatalysts for sustainable energy applications. Prog Mater Sci, In press, 2020; 1-54.

[2] Wang J, Yue X, Yang Y, Sirisomboonchai S, Wang P, Ma X, Abudula A, Guan G. Earth-abundant transition-metal-based bifunctional catalysts for overall electrochemical water splitting: A review. J Alloys Comp 2020; 819(153346): 1-23.

[3] Shervedani RK, Alinoori AH, Madram AR. Electrocatalytic activities of nickel-phosphorous composite coating reinforced with codeposited graphite carbon for hydrogen evolution reaction in alkaline solution. J New Mater Electrochem Syst 2008; 11: 259-265.

[4] Safizadeh F, Ghali E, Houlachi G. Electrocatalysis developments for hydrogen evolution reaction in alkaline solutions A Review. Int J Hydrogen Energy 2015; 40: 256-274.

[5] Paunovic P, Dimitrov AT, Popovski O, Slavkov D, Jordanov SH. Effect of carbon nanotubes support in improving the performance of mixed electrocatalysts for hydrogen evolution. Macedonian J Chem Chem Eng 2007; 26(2):87-93.

[6] Jin Z, Zhang L. Performance of Ni-Cu bimetallic co-catalyst g-C3N4 nanosheets for improving hydrogen evolution. J Mater Sci Technol, 2020; 49:144-156.

[7] Xiang R, Duan Y, Tong C, Peng L, Wang J, Shah SSA, Najam T, Huang X, at al. Self-standing FeCo prussian blue analogue derived $\mathrm{FeCo} / \mathrm{C}$ and $\mathrm{FeCoP} / \mathrm{C}$ nanosheet arrays for cost-effective electrocatalytic water splitting. Electrochim. Acta 2019; 302: 45-55.

[8] Sun J, Zhu D, Sun Y, Ma L, Guo J, Liu Q, Zhang X. Hybrid NiCo hydrogen carbonate with Pt nanoparticles on nickel foam for alkaline water hydrogen evolution. Journal of Alloys and Compounds 2020; 833(155131): 1-8.

[9] Wang Y, Pan L, Chen Y, Shen G, Wang L, Zhang X, Zou J. Mo-doped Ni-based catalyst for remarkably enhancing catalytic hydrogen evolution of hydrogen-storage materials, Int J Hydrogen Energy 2020; 45: 15560-15570.

[10] Zhao G, Lin Y, Rui K, Zhou Q, Chen Y, Dou SX, Sun W. Epitaxial growth of Ni(OH)2 nanoclusters on MoS2 nanosheets for enhanced alkaline hydrogen evolution reaction. Nanoscale, 2018;10:19074-19081.

[11] Solmaz R, Döner A, Doğrubaş M, Erdogan IY, Kardaş G. Enhancement of electrochemical activity of Raney type NiZn coatings by modifying with PtRu binary deposits: Application for alkaline water electrolysis. Int J Hydrogen Energy, 2016; 41: 1432-1440.

[12] Crnkovic FC, Machado SAS, Avaca LA. Electrochemical and morphological studies of electrodeposited Ni-Fe-Mo-Zn alloys tailored for water electrolysis. Int J Hydrogen Energy 2004; 29: 249-254.

[13] Solmaz R, Döner A, Kardaş G. Preparation, characterization and application of alkaline leached CuNiZn ternary coatings for long-term electrolysis in alkaline solution. Int J Hydrogen Energy 2010; 35: 10045-10049.

[14] Döner A, Solmaz R, Kardaş G. Fabrication and characterization of alkaline leached $\mathrm{CuZn} / \mathrm{Cu}$ electrode as anode material for direct methanol fuel cell. Energy 2015; 90: 1144-1151.

[15] Akshatha R. Shetty, Ampar Chitharanjan Hegde, Effect of $\mathrm{TiO}_{2}$ on electrocatalytic behavior of Ni-Mo alloy coating for hydrogen energy. Mater Sci Energy Technol 2018; 1: 97-105. 
[16] Burke LD, Collins JA, Role of surface defects in the electrocatalytic behaviour of copper in base. Journal of Applied Electrochemistry, 1999;29:1427-1438.

[17] Burke LD, Collins JA, Murphy MA, Redox and electrocatalytic activity of copper in base at unusually low, premonolayer potentials J Solid State Electrochem 1999;4:34-41.

[18] Pyun CH, Park SM. Insitu spectro electrochemical studies on anodic-oxidation of copper in alkaline-solution. J Electrochem Soc 1986; 132: 2024-230.

[19] Abd El Haleem SM, Ateya BG. Cyclic voltametry of copper in sodium hydroxide solutions. J Electroanal Chem 1981; 117:309-319.

[20] Marioli JM, Kuwana T. Electrochemical characterization of carbohydrate oxidation at copper electrode. Electrochim Acta 1992; 37: 1187-1197.

[21] Burke LD, Ahern MJG, Ryan TG. An investigation of the anodic behavior of copper and its anodically produced oxides in aqueous solutions of high pH. J Electrochem Soc 1990; 137: 553-561.

[22] Marioli JM, Kuwana T, Electrochemical Characterization of Carbohydrate Oxidation at Copper Electrodes. Electrochim. Acta, 1992;37:1187-1197.

[23] Jayalakshmi M, Balasubramanian K,Cyclic Voltammetric Behavior of Copper Powder Immobilized on Paraffin Impregnated Graphite Electrode in Dilute Alkali Solution. Int. J. Electrochem. Sci. 2008;3:1277 - 1287.

[24] Heli H, Jafarian M, Mahjani MG, Gobal F, Electro-oxidation of methanol on copper in alkaline solution. Electrochim. Acta, 2004;49:4999-5006.

[25] Raj MA, Arumainathan S. Comparative study of hydrogen evolution behavior of Nickel Cobalt and Nickel Cobalt Magnesium alloy film prepared by pulsed electrodeposition. Vacuum 2019; 160: 461-466.

[26] Wang K, Si Y, Lv Z, Yu T, Liu X, Wang G, Xie G, Jiang L. Efficient and stable Ni-Co-Fe-P nanosheet arrays on Ni foam for alkaline and neutral hydrogen evolution. Int J Hydrogen Energy 2020; 45: 2504-2512.

[27] Chen Z, Duan X, Wei W, Wang S, Ni B. Recent advances in transition metal-based electrocatalysts for alkaline hydrogen evolution. J. Mater. Chem. A, 2019; 7: 14971-15005.

[28] Liu Y, Lu H, Kou X. Electrodeposited Ni-Co-Sn alloy as a highly efficient electrocatalyst for water splitting. Int J Hydrogen Energy 2019; 44: 8099-8108.

[29] Yu L, Lei T, Nan B, Jiang Y, He Y, Liu CT, Characteristics of a sintered porous Ni-Cu alloy cathode for hydrogen production in a potassium hydroxide solution. Energy 2016;97:498-505.

[30] He X, Xu F, Li F, Liu L, Wang Y, Deng N, Zhu Y, He J, Composition-performance relationship of NixCuy nanoalloys as hydrogen evolution electrocatalyst. J Electroanal Chem 2017;799:235-241.

[31] Li Y, Zhang X, Hu A, Li M, Morphological variation of electrodeposited nanostructured Ni-Co alloy electrodes and their property for hydrogen evolution reaction. Int J Hydrogen Energy 2018; 43: 22012-22020.

[32] Liu H, Zeng S, He P, Dong F, He M, Zhang Y, Wang S, Li C, Liu M, Jia L, Samarium oxide modified Ni-Co nanosheets based three-dimensional honeycomb film on nickel foam: A highly efficient electrocatalyst for hydrogen evolution reaction. Electrochimica Acta 2019;299:405-414.

[33] Shetty S, Hegde AC, Magnetically Induced Electrodeposition of Ni-Mo Alloy for Hydrogen Evolution Reaction. Electrocatalysis 2017;8:179-188.

[34] Gomez MJ, Franceschini EA, Lacconi GI, Ni and NixCoy Alloys Electrodeposited on Stainless Steel AISI 316L for Hydrogen Evolution Reaction. Electrocatalysis 2018;9:459-470.

[35] Miulovic SM, Lj S. Maslovara, Perovic IM, Nikolic VM, Kaninski MPM. Electrocatalytic activity of ZnCoMo based ionic activators for alkaline hydrogen evolution-Part II. Appl. Catal. A 2013; 451: 220- 226.

[36] Telli E, Farsak M, Kardaş G. Investigation of noble metal loading CoWZn electrode for HER. Int J Hydrogen Energy 2017; 42: 23260-23267.

[37] M.J. Giz, S.C. Bento, E.R. Gonzalez, NiFeZn codeposit as a cathode material for the production of hydrogen by water electrolysis. Int J Hydrogen Energy 2000; 25: 621-626.

[38] Jin T, Liu X, Wang H, Wu X, Zhang Y. Mechanochemical-assisted synthesis of ternary Ru-Ni-S pyrite analogue for enhanced hydrogen evolution performance. Carbon 2020; 162: 172-180.

[39] Zhu M, Yan Y, Yan Q, Yin J, Cheng K, Ye K, Zhu K, Yan J, et al. In situ growth of $\mathrm{Ni}_{0,85} \mathrm{Se}$ on graphene as a robust electrocatalyst for hydrogen evolution reaction. Int J Hydrogen Energy 2020; 45: 10486-10493. 